\title{
ECOCÍDIO COMO INSTRUMENTO DE PROTEÇÃO TRANSNACIONAL DO
}

\author{
MEIO AMBIENTE
}

Andyara Luisa Miglioranzi de Rosso ${ }^{1}$

Carla Piffer ${ }^{2}$

\begin{abstract}
RESUMO
O presente estudo aborda o ecocídio como a prática de condutas lesivas ao meio ambiente caracterizadas como crimes ambientais de grandes proporções, globais e de alcance internacional. Seu objetivo geral é verificar se o ecocídio se apresenta como um instrumento de proteção transnacional do meio ambiente. A fim de alcançar o objetivo geral ora proposto, este estudo inicia sua análise na seara dos direitos humanos e direitos fundamentais, a fim de enquadrar o meio ambiente na categoria de novos direitos. Na sequência, são tecidas considerações acerca do surgimento dos estudos sobre o ecocídio e, ao final, analisa-se a necessidade de seu reconhecimento para a efetiva proteção transnacional do meio ambiente. Em sede de considerações finais, justifica-se que o ecocídio necessita, urgentemente de regulamentação na seara internacional, vez que os danos causados ao meio ambiente são de proporções transnacionais, apresentando-se este, portanto, como instrumento de efetiva proteção transnacional do planeta terra. Na fase de investigação foi utilizado o método indutivo, na fase de tratamento de dados o método cartesiano, e no relatório dos resultados foi empregada a base lógica indutiva.
\end{abstract}

Palavras-chave: Ecocídio; Meio Ambiente; Novos direitos; Transnacionalidade.

\section{ECOCIDE AS A TRANSNATIONAL PROTECTION INSTRUMENT FOR THE}

\section{ENVIRONMENT}

\section{ABSTRACT}

The present study approaches ecocide as the practice of environmentally harmful conduct characterized as major environmental crimes, global and international in scope. Its general objective is to verify if ecocide presents itself as an instrument of transnational protection of the environment. In order to achieve the general objective now proposed, this study begins its analysis in the area of human rights and fundamental rights, in order to fit the environment into the category of new rights. Following, considerations are made about the emergence of studies on ecocide and, in the end, the need for their recognition for the effective transnational protection of the environment is analyzed. In light of the final considerations, it is justified that ecocide urgently needs regulation in the international area, since the damage caused to the environment is of transnational

\footnotetext{
${ }^{1}$ Mestranda em Ciência Jurídica pela Universidade do Vale do Itajaí, com dupla titulação com a Universidade de Alicante/Espanha. E-mail: andyaraluisa@gmail.com

2 Professora Permanente dos Programas de Mestrado e Doutorado em Ciência Jurídica - PPCJ - UNIVALI. Professora permanente do Mestrado Internacional Profissional em Direito das Migrações Transnacionais UNIVALI. Professora de Pós-graduação Lato sensu. Professora de Graduação. Pós-doutora pela Universidade do Vale do Itajaí - UNIVALI. Pós-doutora pela Universidade de Passo Fundo - UPF. Doutora em Diritto pubblico pela Università degli Studi de Perugia - Facoltà di Giurisprudenza- Itália. Doutora em Ciência Jurídica (UNIVALI). Mestre em Ciência Jurídica (UNIVALI). MBA em Direito da Economia e da Empresa/FGV. Graduada em Direito. ORCID:https://orcid.org/0000-0002-1294-7248. E-mail: carlapiffer@univali.br
} 
proportions, thus presenting itself as an instrument of effective transnational protection of planet earth. In the investigation phase, the inductive method was used, in the data processing phase the Cartesian method, and in the results report the inductive logic base was used.

Keywords: Ecocide; Environment; New rights; Transnationality.

\section{INTRODUÇÃO}

Desde 1972, a partir da Conferência de Estocolmo, ampliaram-se os instrumentos jurídicos de proteção ao meio ambiente. Não obstante todo o desenvolvimento obtido desde então, até o momento não se verificou a implementação de sanções jurídicas capazes de impedir ou frear as condutas nocivas, especialmente as de grandes proporções, praticadas contra o meio embiente.

Diante deste dilema, o presente artigo pretende, sob a ótico dos "novos direitos", analisar o ecocídio a fim de verificar se pode ser ele um instrumento de proteção transnacional do meio ambiente.

Tendo em vista que muitos dos desastres ambientais de grande proporção são provocados pela ação humana, são os próprios seres humanos os afetados pelas suas próprias atitudes lesivas. A fim de alcançar o objetivo geral ora proposto, este estudo inicia sua análise na seara dos direitos humanos e direitos fundamentais, a fim de enquadrar o meio ambiente na categoria de novos direitos. Na sequência, são tecidas considerações acerca do surgimento dos estudos sobre o ecocídio e, ao final, analisa-se a necessidade de seu reconhecimento para a efetiva proteção transnacional do meio ambiente.

Quanto à metodologia empregada neste trabalho (PASOLD, 2018), registra-se que, na fase de investigação foi utilizado o método indutivo, na fase de tratamento de dados o método cartesiano, e no relatório dos resultados foi empregada a base lógica indutiva.

\section{MEIO AMBIENTE E “NOVOS” DIREITOS}

Uma das primeiras dificuldades ante a complexidade do tema dos direitos humanos é a terminologia a ser adotada. Há uma ampla discussão na doutrina no que se refere à utilização e definição terminológica das expressões "direitos fundamentais", "direitos humanos", "direitos humanos fundamentais", dentre outras.

Sobre a nomenclatura “direitos fundamentais”, leciona Branco (2009, p. 278), que são aqueles relacionados com posições básicas das pessoas e positivados em diplomas normativos de cada Estado. Nas palavras do mesmo autor "são direitos que vigem numa ordem jurídica concreta, sendo, por isso, garantidos e limitados no espaço e no tempo, pois são assegurados na medida em que cada 
Estado os consagra".

Por sua vez, segundo o mesmo autor, a expressão "direitos humanos" ou "direitos do homem" faz referência às reivindicações contínuas essenciais ao homem. São direitos demandados em bases jusnaturalistas que prescindem uma positivação em determinada ordem jurídica particular. Os "direitos humanos" têm vocação universalista, supranacional, e designam pretensões de respeito à pessoa humana, inseridas em documentos de direito internacional (BRANCO, 2009, p. 278).

Para fins deste estudo, será utilizada a distinção referida, admitindo-se utilização diversa, quando necessário para manter-se fiel às citações.

Há 70 anos, a afirmação universal dos Direitos Humanos, com registro a partir da Declaração Universal de Direitos Humanos de 1948, não poderia prever os desafios tecnológicos e climáticos que emergiram frente à crise socioambiental da modernidade.

O jurista francês Karel Vasak, em 1979, durante a Conferência proferida no Instituto Internacional de Direitos Humanos de Estrasburgo, na França, apresentou a teoria das gerações dos direitos. Vasak classificou os Direitos Humanos em três gerações associadas, cada uma, a um dos componentes da Revolução Francesa: liberdade, igualdade e fraternidade.

Posteriormente, alguns doutrinadores, como o constitucionalista Bonavides (2011, p. 570), incluíram uma quarta dimensão, composta pelos direitos à democracia, à informação e ao pluralismo, figurando como garantidores de uma legítima e possível globalização política.

Fensterseifer (2008, p. 142-152), por sua vez, sintetizou a construção histórica por meio das dimensões dos direitos fundamentais, a partir do marco do Estado de Direito e dos modelos de Estado, nos seus moldes Liberal, Social e Socioambiental.

O primeiro fez emergir os direitos fundamentais de primeira dimensão, que expressam direitos civis e políticos, como direito à vida e à integridade física. A principal característica destes direitos está na natureza negativa ou defensiva em face do Estado, de forma a não interferir na esfera privada, sob o alicerce do princípio da liberdade. A condição do ser humano, como titular de direitos fundamentais, estava focada sob a ótica individualista que desprezava os valores comunitários (FENSTERSEIFER, 2008, p. 145).

Já o marco do Estado Social, traduz os direitos fundamentais de segunda dimensão, que configuram os direitos sociais, econômicos e culturais, como direito à saúde e à educação, passando de uma postura negativa (Estado Liberal) para um modo positivo ou prestacional, com a função ativa de efetivar e propiciar as condições materiais necessárias para o gozo destes direitos a todos os cidadãos, ocupando-se com a questão da igualdade (FENSTERSEIFER, 2008, p. 146).

O terceiro, como Estado Socioambiental (FENSTERSEIFER, 2008, p. 146), marco dos direitos fundamentais de terceira dimensão que incorporaram um conteúdo de universalidade e tratam 
de questões difusas e transfronteiriças, como os direitos de solidariedade, direito à paz e o direito ao Meio Ambiente saudável. São direitos de titularidade difusa ou coletiva, uma vez que se destinam à proteção de grupos humanos (família povo, nação), traduzindo o conteúdo humanista e universal desses direitos (SARLET, 2018, p. 48).

E é na terceira dimensão que se debruça o presente estudo, especialmente no direito ao ambiente, cuja natureza transindividual reside na titularidade indefinida e indeterminável, definindo seu caráter transfronteiriço. Parte-se do pressuposto de que os problemas ambientais são globais, assertiva que passa a demandar ações além dos próprios Estados nacionais. São, desta forma, direitos que reclamam uma nova visão de solidariedade.

Marcos Leite Garcia (2010) ensina, a partir da teoria das linhas de evolução do surgimento progressivo dos direitos fundamentais, desenvolvida por Peces-Barba Martínez (1991), que os direitos humanos são um fenômeno da Modernidade. Tal leitura desenvolvida por Garcia (2010), se fundamenta em quatro processos históricos: 1) inicia-se com o processo de positivação e apresenta equivalência com os direitos primeira dimensão, notadamente o de liberdade; 2) o segundo processo é o de generalização, identificado pela extensão do reconhecimento e proteção dos direitos de uma classe, correspondente à segunda dimensão, atrelada aos direitos sociais; 3) é identificado com o processo de internacionalização, de difícil concretização, caminhando-se para a criação de sistemas de proteção internacional, para além fronteiras, e que envolvam toda a Comunidade Internacional ou Regional; 4) e finalmente, o autor apresenta o processo de especificação, momento em que a situação concreta da pessoa é considerada ou quando passa a ser alvo de direitos, como o direito a um meio ambiente saudável ou à paz. São direitos que integram terceira dimensão.

Ferreira Filho (1999, p. 57) identifica os "novos" direitos da terceira dimensão como direitos de solidariedade, por expressarem direitos de grupos que trazem desafios relacionados à qualidade de vida e à solidariedade entre os seres humanos de todas as raças ou nações.

Neste sentido, Peces-Barba Martínez (1991, p. 17) repisa a importância do conceito jurídico da solidariedade da seguinte forma:

\begin{abstract}
Importa subrayar la importancia del paso del valor moral «solidaridad» al concepto jurídico, derechos económicos, sociales y culturales, que situá el problema em el ámbito de una sociedad política, de un Estado y de su Derecho, sin perjuicio de la influencia ética y religiosa. Este punto de vista me parece decisivo, porque configura el contenido de las acciones positivas basadas em la idea de solidaridad y es el objetivo perseguido por la acción de los poderes públicos y por los fines de las organizaciones sociales que se dedican a este tipo de prestaciones.
\end{abstract}

A solidariedade como princípio que transcende para a tutela ambiental nas dimensões intercomunitária e intergeracional, indispensável para a efetividade da tutela ambiental derivada das próprias exigências da justiça distributiva, é remontada por Mateo (1995, p. 48) que expõe: 
Más allá de los límites que acotan las soberanías de los Estados nacionales, la solidaridad debe ser un imperativo no sólo ético, sino también práctico, impuesto por la base internacional de la mayoría de los sistemas naturales y por la necesidad de limitar, en aras del desarrollo sostenible, un excesivo uso de los recursos, lo que requiere obligadamente de asistencias y transvases. Así la solidaridad aparece como complemento y a la vez consecuencia y corolario de la puesta en vigor de los principios ante enunciados.

A solidariedade expressa, portanto, a necessidade de coexistência dos seres humanos em um corpo social, configurando a teia de relações intersubjetivas e sociais nos espaços da comunidade estatal. Necessita-se, portanto, transpor a solidariedade ao plano jurídico-normativo como pilar para a construção de uma sociedade e de um Estado guardiões dos direitos fundamentais (FENSTERSEIFER, 2008). A força normativa da solidariedade no âmbito da "juridicizada sociedade contemporânea", tornou-se um princípio geral do ordenamento jurídico, dotado de força normativa e capaz de tutelar o devido respeito a cada um, notadamente na defesa do meio ambiente.

O direito ao meio ambiente, de terceira dimensão e classificado dentre os "novos" direitos", enuncia um novo bem jurídico a ser tutelado e protegido, e possui relação intrínseca com o ecocídio. Nesse diapasão, passa-se a analisar o processo de construção do ecocídio, sob o viés de instrumento de proteção transnacional do direito fundamental ao meio ambiente.

\section{BREVE ESCORÇO SOBRE O CRIME DE ECOCÍDIO}

O direito ao meio ambiente, inserido na gama dos "novos" direitos, são considerados transfronteiriços e transnacionais (GARCIA, 2010), porque sua proteção não é restrita às tradicionais fronteiras dos Estados. Por esta característica, a tutela do meio ambiente através do Direito Penal ganha destaque no cenário internacional.

Apesar do avanço legislativo e normativo por meio de acordos internacionais, especialmente durante a Convenção da Nações Unidas de Estocolmo, em 1972, quando a tutela do ambiente foi reconhecida como um direito humano autonomamente reconhecido, os danos ambientais aumentam em larga escala. Não há um documento oficial internacional que proíba, explicitamente, o ecocídio. Mas afinal, o que seria o ecocídio?

Na conferência de 1972, Olof Palme, primeiro ministro da Suécia, falou da guerra do Vietnã como um ecocídio e criticou as Nações Unidas por não terem apoiado a tipificação do ecocídio como um crime contra o meio ambiente.

Com os impactos negativos causados pela globalização e os riscos desenvolvidos pela sociedade, a falta de solução de problemas em uma sociedade de risco justifica o aumento do número de movimentos que buscam uma regulação internacional mais severa. Dentre os grupos, destaca-se a advogada escocesa Polly Higgins, que contribuiu sobremaneira para a construção de um conceito para 
ecocídio e atuou, à frente de grupos como End Ecocide on Earth e Eradicating Ecocide, na busca da ampliação de instrumentos jurídicos protetivos e punitivos - Lei do ecocídio (ECOCIDELAW).

Sobre a proposta do Eradicating Ecocide enfatiza-se:

Por el momento no existe ninguna ley que ponga fin al ecocidio. Sin embargo, al
convertirlo en un crimen internacional, las naciones signatarias del Estatuto de Roma
emprenderían acciones judiciales. (Este es el caso incluso si la persona o Estado
involucrado no es signatario, ya que el Tribunal Penal Internacional tiene poderes para
intervenir en ciertas circunstancias.) Actualmente 124 Estados son signatarios del
Estatuto de Roma; el primer paso es simplemente que uno o más Estados propongan
el crimen del ecocidio. Una vez presentada, la enmienda queda abierta a los
signatarios y al alcanzar una mayoría de dos tercios, se convierte en un derecho penal
internacional (ECOCIDELAW).

Polly Higgins propôs, em abril de 2010, a Lei do Ecocídio, que busca emendar o Estatuto de Roma e representa "uma via legal que abalará significativamente o caos climático, protegerá milhões de vidas e evitará danos sérios, ao impor responsabilidade estatal e corporativa a atividades industriais e climáticas perigosas" (ERATICATING ECOCIDE).

Nenhum dos acordos internacionais vigentes proíbe explicitamente o ecocídio. O poder do crime de ecocídio é criar um dever legal de cuidado que obriga os agentes a prestar contas perante o Tribunal Penal Internacional.

Há dois projetos para a inclusão de crimes ambientais no rol abrangido pela jurisdição do Tribunal Penal Internacional: uma proposta é para que as grandes catástrofes ambientais sejam reconhecidas como um crime contra a natureza, a paz e as futuras gerações (crime de ecocídio como tipo autônomo); outra vertente, é pela ampliação do conceito do crime contra a humanidade previsto na alínea $k$ do artigo $7^{\circ}$ do Estatuto de Roma, que inclui “outros atos desumanos de caráter semelhante, que causem intencionalmente grande sofrimento, ou afetem gravemente a integridade física ou a saúde física ou mental (BRASIL, 2002).

O movimento Eradicating Ecocide define o crime de ecocídio como sendo um dano extenso, a destruição ou a perda de um ou vários ecossistemas de um determinado território, seja por ação humana ou por outras causas, de tal forma que o gozo ao direito à paz, à saúde e à qualidade de vida pelos habitantes daquele território tenha sido ou venha a ser severamente prejudicada.

A Lei do Ecocídio apresentada pelo grupo Eradicating Ecocide busca inclúi-lo como a quinta espécie de crime previsto pelo Estatuto de Roma, cuja proposta pode ser apreciada na sequência: El delito de Ecocidio es:

"Cualquier acto u omisión cometido imprudentemente en tiempos de paz o de conflicto por cualquier persona de alto rango en el curso de la actividad del Estado, de una empresa, o de cualquier otra entidad que cause o contribuya a una grave pérdida o daño ecológico, climático o cultural o a la destrucción del ecosistema o ecosistemas de un territorio o territorios determinados, de manera que el disfrute pacífico por parte de los habitantes se haya visto o vaya a verse gravemente menoscabado." 


\section{[...].(ERATICATING ECOCIDE)}

Estudos e pesquisas como a do grupo Eradicanting Ecocid estão sendo desenvolvidos para a construção de uma proposta viável de tipificação do crime de ecocídio, a fim de tutelar o "novo" direito ao meio ambiente, tendo em vista que as condutas criminosas não estão padronizadas, e esta variação na definição de conceitos e penas favorece o incremento da criminalidade ambiental, especialmente naqueles crimes com consequências regionais ou globais, características verificáveis comumente nos crimes ambientais (BROCHADO NETO; MONT’ ALVERENE, 2018).

Outrossim, diferente da proposta de inclusão do ecocídio como um crime autônomo, a ampliação do conceito do crime contra a humanidade previsto no Estatuto de Roma tem recebido duras críticas pela doutrina especializada. Para Gordilho e Ravazzano (2017), por exemplo, as definições trazidas para esta ampliação não são suficientes para enquadrar o ecocídio como um crime contra a humanidade.

Para que a conduta resultante em um dano ambiental que atinja gravemente a integridade física ou a saúde mental da população, de acordo com o caput do artigo $7^{\circ}$, o delito deve ser praticado no quadro de um ataque, generalizado ou sistemático, dirigido a uma população civil, de forma que a caracterização do ecocídio passaria a exigir a prova desta particularidade:

Assim, para que a prática do ecocídio seja considera um crime contra a humanidade,
a acusação deve provar de que conduta praticada foi um ataque generalizado ou
sistemático que provocou um dano ambiental o qual, por sua vez, resultou em um
grave comprometimento da saúde física ou mental de uma população civil - como por
exemplo, o lançamento deliberado de um produto tóxico em um rio que abasteça a
população local - caso contrário, estar-se-á admitindo a analogia in malam partem,
proibida nos Estados Democráticos de Direito. (GORDILHO; RAVAZZANO, 2017,
p. 698) Para Freeland (2005, p. 135), a definição trazida pelo Estatuto de Roma no que se refere aos crimes contra a humanidade possibilitaria a inclusão dos crimes ambientais no âmbito de julgamento do TPI.

Quer parecer, porém, que a definição constante do Estatuto de Roma facultaria inserir os crimes ambientais em seu âmbito. As opções mais prováveis nesse sentido seriam os atos enquadrados nos Artigos $7^{\circ}(1)(\mathrm{h})$ e $7^{\circ}(1)(\mathrm{k})$ do Estatuto de Roma. O Artigo $7^{\circ}(1)(h)$ refere-se à "[...] perseguição de um grupo ou comunidade que possa ser identificado, por motivos políticos, raciais, nacionais, étnicos, culturais, religiosos ou de gênero, $[. .$.$] ou em função de outros critérios universalmente reconhecidos como$ inaceitáveis no direito internacional [...]" (grifo nosso). No Artigo $7^{\circ}$ (2)(g) a caracterização dos grupos é mais ampla do que para o Crime de Genocídio. O termo "perseguição" vem definido como "privação intencional e grave de direitos fundamentais em violação do direito internacional [...]".

O autor (2005, p. 136) entende que o atual conceito de Crimes contra a Humanidade definido no Estatuto de Roma representa uma ferramenta possível para denunciar crimes ambientais perante o TPI, se fazendo necessário comprovar a presença dos demais elementos do crime, a 
ocorrência de ataque, generalizado ou sistemático contra qualquer população civil, por exemplo.

Recentemente, em setembro de 2016, o escritório da Promotoria do Tribunal Penal Internacional emitiu um documento sobre a política de seleção e priorização dos casos da Corte, que passará a considerar os impactos de um crime no momento de analisar a sua gravidade, o que representa uma política inserida nos debates sobre novos mecanismos internacionais para julgamento de crimes ambientais (TRIBUNAL PENAL INTERNACIONAL, 2016).

No âmbito nacional, cumpre mencionar que a Comissão de Meio Ambiente do Senado (BRASIL, 2019) brasileiro aprovou no dia 10 de outubro do corrente o Projeto de Lei n. 2.787/19, que tipifica o crime de ecocídio, quando a pessoa causa desastre ambiental com destruição significativa da flora ou mortandade de animais. Referido texto segue para a Comissão de Constituição e Justiça da Casa, seguindo seu trâmite regimental até eventual aprovação. Este projeto altera a Lei n ${ }^{\circ}$ 9.605, de 12 de fevereiro de 1998 (Lei de Crimes Ambientais), na tentativa de inserir na citada lei artigos que tipificam crimes de ecocídio, como o desastre ambiental com destruição significativa da flora ou mortandade de animais e o rompimento de barragem pela inobservância de legislação, por exemplo.

Independentemente da existência ou não de tipificação penal no âmbito interno, não se pode olvidar que qualquer desastre ambiental possui abrangência transnacional, pois seus efeitos não são adstritos às fronteiras geográficas dos Estados e necessitam, portanto, de instrumentos eficazes que promovam a proteção transnacional no meio ambiente. Este será o assunto abordado na sequência.

\section{ECOCÍDIO E A PROTEÇÃO TRANSNACIONAL DO MEIO AMBIENTE}

Embora as legislações nacional e internacional não disponham de uma tipificação específica para o crime internacional (ou transnacional) ambiental, salvo para aquele cometido num contexto de conflito armado, é irrefutável a impossibilidade de restringir localmente os efeitos causados por ofensas ao meio ambiente. O problema ambiental é um dado evidente da emergência de uma lógica transnacional.

Entende-se por transnacionalidade, conforme propõem Cruz e Bodnar (2010) que o prefixo trans indica uma estrutura pública transnacional que perpassa vários estados e denota a emergência de uma nova definição construída reflexivamente a partir da transferência e transformação dos espaços e modelos nacionais. No tocante à questão ambiental e sua abrangência transnacional, o autor menciona que esta

[...] apresenta vocação espacialmente planetária e denuncia que a organização da sociedade humana em Estados, pretensamente soberanos, faz com que o âmbito de aplicação das suas normas seja restrito aos limites das suas fronteiras. Tal configuração não é apropriada para a questão ambiental, já que o objeto sobre o que se projeta é insuscetível de submeter-se às caprichosas linhas dos estados nacionais. 
A proteção da biosfera não é, portanto, compatível com este esquema e tampouco os ordenamentos jurídicos nacionais e internacionais que pretendem protegê-la, pois faltam ferramentas comuns a todos os cidadãos e países (CRUZ, 2012, p. 136-137).

No pano de fundo do fenômeno da transnacionalidade está a necessidade de se trabalhar elementos de compreensão para fornecer respostas às atuais demandas que, no caso do presente estudo, relacionam-se com a proteção do meio ambiente através da tipificação do crime de ecocídio.

Sobre a discussão referente à transnacionalidade, Piffer (2014, p. 124-125) ensina que abordá-la significa cogitar a possibilidade de modificar as concepções sobre as relações transpassantes que afetam direta ou indiretamente a todos, a fim de ordenar um claro sendo de responsabilidade com relação aos efeitos de ações políticas e econômicas em um mundo globalizado.

Acompanhando outros efeitos da globalização (STELZER, 2011, p. 18-19), os problemas ambientais afetam todo o planeta. Não é possível isolar as consequências dentro das fronteiras territoriais, e isso levou a uma tomada de consciência sob a ótica de um meio ambiente único, cuja regulamentação racional somente se efetivaria por meio de um sistema normativo também único, determinado inicialmente pelo direito internacional (SOARES, 2003, p. 39).

Soares (2003, p. 40) aponta duas grandes questões que levaram ao deslocamento da discussão sobre o meio ambiente para os foros internacionais: a) a necessidade de cooperação internacional como condição indispensável para que houvesse, ao mesmo tempo, idêntica providência dos Estados para fins de preservação ambiental; e, b) o indicativo de que resultados significativos na prevenção de grandes tragédias ambientais somente seriam atingidos por meio de "uma efetiva coordenação, em nível internacional, dos esforços e das políticas ambientalistas, adotados nos ordenamentos jurídicos nacionais".

Com a influência da diplomacia multilateral da ONU, os Estados passaram a canalizar suas reivindicações em prol de uma política conservacionista do meio ambiente elevada à escala mundial e novos atores sociais passaram a ter voz ativa, ante a ampliação da participação na discussão e execução dos programas e políticas socias, o que originou o conceito de governança que, em 1994, foi definida pela Comissão sobre Governança Global da ONU como "a totalidade das diversas maneiras pelas quais os indivíduos e as instituições, públicas e privadas, administram seus problemas comuns" (SOARES, 2003, p. 41).

Especificamente na questão do clima, pode-se observar uma desestruturação no caminhar das agendas internacionais, a exemplo da retirada da oferta dos países da américa latina, Brasil e Chile, para sediar realização da Conferência Mundial do Clima de 2019 (COP 25).

$\mathrm{O}$ anúncio gerou incerteza sobre a luta internacional contra as mudanças climáticas, em um momento em que a ciência alerta para as graves consequências do aquecimento global, a 
preocupação não parece estar sendo acompanhada claramente pelas lideranças políticas internacionais como uma emergência global.

A Conferência será sediada pela Espanha e está programada para ser realizada entre os dias 2 a 13 de dezembro deste ano. Reunirá governos, setor privado, sociedade civil, autoridades locais e outras organizações internacionais para desenvolver soluções ambiciosas em seis áreas: a transição global para energia renovável; infraestrutura e cidades sustentáveis; agricultura e manejo sustentável de oceanos e florestas; adaptação aos impactos climáticos; e a convergência de financiamento público e privado com uma economia líquida zero de emissões (SOARES, 2003, p. 41).

Para o desiderato de avançar na proteção transnacional do meio ambiente, a atuação dos organismos de governança e da sociedade civil, a exemplo do movimento Eradicating Ecocid, avançam no debate para uma legislação internacional, via Tribunal Penal Internacional, para tipificação do crime de ecocídio.

Mais do que um crime internacional, o ecocídio, que visa proteger o "único meio ambiente do planeta", parece reunir as características necessárias para ser classificado como um crime transnacional, conforme especificado por Piffer e Cruz:

[...] a infração será de caráter transnacional se: a) For cometida em mais de um Estado;

b) For cometida num só Estado, mas uma parte substancial da sua preparação, planeamento, direção e controle tenha lugar em outro Estado; c) For cometida num só Estado, mas envolva a participação de um grupo criminoso organizado que pratique atividades criminosas em mais de um Estado; ou d) For cometida num só Estado, mas produza efeitos substanciais noutro Estado (PIFFER; CRUZ, 2018, p. 21).

Deste modo, a ausência de definição objetiva e precisa para imputação da conduta dos crimes de ecocídio parece se sobressair à urgente proteção do Planeta que desafia o mundo contemporâneo a desenvolver mecanismos legais, nacional e internacionalmente, eficazes no combate às condutas delitivas ambientais de caráter transfronteiriço.

\section{CONSIDERAÇÕES FINAIS}

A degradação e destruição do meio ambiente pelo homem em nome do lucro tem deixado a comunidade internacional em estado de alerta há décadas. A criminalização das condutas contra o meio ambiente, especialmente no âmbito do direito internacional, ainda é um desafio. Desde a década de 70, vem se tentando tipificar o crime de ecocídio, compreendido, como se demonstrou, como a ofensa massiva ao meio ambiente causada pela ação humana.

Verificou-se que o direito ao meio ambiente, neste estudo chamado de "novos direitos", possui como principal característica a desterritorialização e sua dimensão transfronteiriça. Deste modo, sob o viés da transnacionalidade, a questão ambiental demonstra, por si só, a razão da sua natureza 
transnacional.

Outrossim, embora não haja tipificação específica de crime internacional ambiental, salvo para aquele cometido num contexto de conflito armado, entende-se ser premente uma nova abordagem criminal dos danos ambientais, pois uma definição objetiva e precisa para imputação da conduta e a impossibilidade de restringir localmente os efeitos causados por ofensas ao meio ambiente desafia o mundo contemporâneo a desenvolver mecanismos legais, nacional e internacionalmente, eficazes no combate às condutas delitivas ambientais de caráter transfronteiriço.

Deste modo, esta nova abordagem criminal dos danos ambientais, sob a figura do ecocídio se apresenta como um modo eficaz, para não dizer diretamente imprescindível, para promover a proteção transnacional do meio ambiente. Os beneficiados, sem sombra de dúvidas, serão todos nós.

\section{REFERÊNCIAS}

BRANCO, Paulo Gustavo Gonet. Teoria geral dos direitos fundamentais. In: MENDES, Gilmar Ferreira; COELHO, Inocêncio Mártires; BRANCO, Paulo Gustavo Gonet. Curso de direito constitucional. 4 ed. rev. e atual. São Paulo: Saraiva, 2009.

BRASIL. Câmara dos Deputados. PL 2787/2019. Disponível em:

https://www.camara.leg.br/proposicoesWeb/fichadetramitacao?idProposicao=2201529.

Acesso em: 01 nov. 2019.

BONAVIDES, Paulo. Curso de Direito Constitucional. 23. ed. atualizada. São Paulo: Malheiros, 2011.

BROCHADO NETO, Djalma Alvarez; MONT' ALVERENE, Tarin Cristiano Frota.

Ecocídio: proposta de uma política criminalizadora de delitos ambientais internacionais ou tipo penal propriamente dito?. Revista Brasileira de Políticas Públicas, Brasília, v. 8, n. 1, p. 209-226, abril. 2018.

CRUZ, Paulo Marcio; BODNAR, Zenildo. A transnacionalidade e a emergência do Estado e do Direito Transnacionais. In: CRUZ, Paulo Márcio; STELZER, Joana (orgs.). Direito e Transnacionalidade. Juruá: Curitiba, 2010.

CRUZ, Paulo Márcio. Globalização, transnacionalidade e sustentabilidade [recurso eletrônico] /Paulo Márcio Cruz, Zenildo Bodnar; participação especial Gabriel Real Ferrer. Dados eletrônicos. - Itajaí: UNIVALI, 2012

ERATICATING ECOCIDE. Disponível em: https://eradicatingecocide.com. Acesso em: 12 out. 2019.

FENSTERSEIFER, Tiago. Direitos fundamentais e proteção do ambiente: a dimensão ecológica da dignidade humana no marco jurídico-constitucional do Estado Socioambiental de Direito. Porto Alegre: Livraria do Advogado, 2008.

FREELAND, Steven. Direitos humanos, meio ambiente e conflitos: enfrentando os crimes ambientais. Sur - Revista Internacional de Direitos Humanos. vol.2, n.2, 2005. Disponível em: http://www.scielo.br/scielo.php?pid=S1806-

64452005000100006\&script=sci_abstract\&tlng=pt. Acesso em: 14 maio 2019.

GARCIA, Marcos Leite. Reflexões sobre o fenômeno dos "novos" direitos fundamentais e as demandas transnacionais. Revista do Direito, Santa Cruz do Sul, p. 103-129, jan. 2010. ISSN 1982-9957. Disponível em: https://online.unisc.br/seer/index.php/direito/article/view/1801.

Acesso em: 21 out. 2019. 
GONÇALVES, Alcindo. COSTA. José Augusto Fontoura. Governança ambiental global: possibilidades e limites. In GRANZIERA, Maria Luiza Machado. REI, Fernando (coords.). Direito Ambiental Internacional: Avanços e Retrocessos. 40 Anos de Conferência das Nações Unidas. São Paulo: Atlas. 2015.

GORDILHO, Heron José de Santana; RAVAZZANO, Fernanda. Ecocídio e o Tribunal Penal Internacional. Justiça do Direito, v. 31, n. 3, p. 688-704, set/dez 2017. Disponível em: http://seer.upf.br/index.php/rjd/article/view/7841/4648. Acesso em: 10 jun. 2019.

MARTÍN MATEO, Rámon. Manual de Derecho Ambiental. Madri: Trivium, 1995. PASOLD, Cesar Luiz. Metodologia da pesquisa jurídica: teoria e prática. 14 ed. Florianópolis: EMais, 2018

PECES-BARBA MARTÍNEZ, Gregorio. Humanitarismo y Solidariedade social como valores de uma sociedade avanzada. Las entidades no lucrativas de carácter social y humanitario. La Ley: Madrid, 1991. p. 15-62. Disponível em: http://hdl.handle.net/10016/16005. Acesso em: 04 nov. 2019.

PIFFER, Carla. Transnacionalidade e Imigração: a possibilidade de efetivação dos Direitos Humanos dos Transmigrantes diante de Decisões de Regresso na Itália e na União Europeia. Tese (Doutorado em Ciência Universidade do Vale do Itajaí - UNIVALI, Itajaí, 2014. Disponível em http://siaibib01.univali.br/pdf/Carla\%20Piffer.pdf. Acesso em: 5 nov. 2019. PIFFER, Carla. CRUZ, Paulo Márcio. Manifestações do Direito Transnacional e da Transnacionalidade. In PIFFER, Carla. BALDAN, Guilherme Ribeiro. CRUZ, Paulo Marcio (orgs.). Transnacionalidade e sustentabilidade: dificuldades e possibilidades em um mundo em transformação. Porto Velho: Emeron, 2018.

SARLET, Ingo Wolfgang. A eficácia dos direitos fundamentais: uma teoria geral dos direitos fundamentais na perspectiva constitucional. 13. ed. revista, atualizada e ampliada. Porto Alegre: Livraria do Advogado, 2018.

SOARES, Guido Fernando Silva. A proteção internacional do meio ambiente. Barueri, SP: Manole, 2003

TRIBUNAL PENAL INTERNACIONAL. Policy paper on case selection and prioritisation, 2016. Disponível em: https://www.icc-cpi.int/itemsDocuments/20160915_OTP-Policy_CaseSelection_Eng.pdf. Acesso em: 05 nov. 2019. 